\title{
A Farewell
}

\author{
Sudhir Gupta
}

Published online: 16 October 2010

(C) The Author(s) 2010. This article is published with open access at Springerlink.com

Dear Readers:

It is after 31 years when the Journal of Clinical Immunology was founded, and 30 years since its first publication, I retire from the editorship of the Journal of Clinical Immunology effective January 1, 2011.

It was in late 1979, when I was a young faculty member at the memorial Sloan-Kettering Center, and Cornell University Medical College, New York, Professor Henry Kunkel discussed with me a possibility of starting a new journal in clinical immunology. $\mathrm{He}$, as many in the field at that time, was not pleased with the quality of clinical immunology journals. He later convinced me that I should start a new journal in clinical immunology, which I reluctantly accepted. I approached Plenum Press, with whom I had already edited a book on Molecular Aspects of Allergic Diseases, with the idea of starting a new journal. They were receptive and excited, and the journal was founded in mid 1980 with its first publication slated for January, 1981. I put together an outstanding group of associate editors, including Robert Good, Max Cooper, Rebecca Buckley, Kimishige Ishizaka, and John Kersey, a superb advisory board, including Frank Austen, Henry Kunkel, William Paul, Maxime Seligman, Edward Franklin and Thomas Waldman, and a group of highly dedicated editorial board members, which later were changed every 4 years. One of my associate editors thought it was not a good idea to start a new journal and that I might not succeed; however, he agreed to be on the journal. Henry

S. Gupta $(\bowtie)$

Medical Science I, C-240, University of California,

Irvine, CA 92697, USA

e-mail: sgupta@uci.edu did point out some difficulties and obstacles that I might face from my friends and colleagues to maintain a good quality journal, and he emphasized that the quality of papers should never be compromised. I followed his advice and, in doing so initially, may have made a few of my friends unhappy; however, during the last 30 years, the Journal of Clinical Immunology has grown, its impact factor continues to increase, and it has become one of the premier journals in clinical immunology.

Recently, I have taken an International project to develop centers of excellence (COE) in primary immunodeficiency (PID) in India. It is estimated that there may be more than 1 million children and adults in India with PID who are not diagnosed and treated. There are few formally trained physicians/scientists in the area of PID, and the diagnostic facilities are limited. During the last 6 months, I have been successful in convincing and securing support from the Minister of Health and Family Welfare, Director of the Indian Council for Medical Research, the Secretary of the Department of Biotechnology in the Ministry of Science and Technology to establish COE in PID in India. The first COE will be in operation by early 2011. I always wanted to give something back to my own country of birth. I am pleased that I now will have time to dedicate my efforts to develop premier institutions in PID in India, works for my charitable foundation (Foundation for Primary Immunodeficiency), and help thousands of patients with PID in India. There will, however, not be any change in my current position at the University of California at Irvine.

During the last 30 years, I had the pleasure of working with associate editors, advisory board members, and a large number of dedicated editorial board members. The success of the journal is largely because of assistance from associate editors, advice from the most outstanding advisory board, and the rigor and fairness with which editorial board 
members have provided critical reviews of the manuscripts submitted to the journal. I thank you all for the time and efforts, and the quality of reviews that you provided through many years. Since I consider the Journal of Clinical Immunology to be my baby, I leave with some mixed feelings; however, I am pleased that it will be the flagship journal of the Clinical Immunology Society, and the journal will be run by an outstanding editor and a group of dedicated editorial board members.
Good luck to us, and I wish a successful future for the Journal of Clinical Immunology.

Sudhir Gupta, M.D., Ph.D.

Open Access This article is distributed under the terms of the Creative Commons Attribution Noncommercial License which permits any noncommercial use, distribution, and reproduction in any medium, provided the original author(s) and source are credited. 